\section{Posmodernidad y política}

\author{
Angela Ramírez G. *
}

\section{RESUMEN}

El artículo hace un acercamiento teóricofilosófico al concepto de posmodernidad Toma como punto de análisis el concepto de politica posmoderna de Agnes Heller y Ferenc Féher para explicar el desencanto politico de la sociedad civil ante la imposibilidad de los Estados Nacionales de ser verdaderos representantes de la pluralidad cultural de América Latina.

\section{PALABRAS CLAVE}

Politica, posmodernidad, democracia participativa

\footnotetext{
ABSTRACT

The article approaches the theoretical-philosophical concept of postmodernism. The object of the analysis is the concept of post modern politics of Agnes Heller and Ferenc Feher. It is used to explain the political deceit of the civil society due to the incompetence of National States of becoming true representatives of Latin American cultural plurality.

* Licenciada en Comunicación Social y bachiller en Ciencias Políticas. Profesora de la Escuela de Estudios Generales, UCR, y de la Escuela de Ciencias Sociales y Humanidades de la UNED.

Rec. 10-8-05 / Acep. 28-9-05
}

\section{KEY WORDS}

Politics, Post modernity, Participative Democracy

\author{
¿De dónde venimos? \\ ¿dónde estamos? \\ ¿a dónde vamos?
}

Gauguin

\section{INTRODUCCIÓN}

El siguiente texto consta de dos partes: en la primera, se aborda el concepto de posmodernidad desde sus orígenes filosóficos, históricos y principales críticas que se le hacen a la modernidad. La segunda parte, tiene como finalidad caracterizar la política desde la posmodernidad y se plantea la interrogante en torno a sí es posible una política posmoderna en América Latina.

\section{Orígenes filosóficos}

Posmodernidad es un concepto sumamente complejo que aún no ha podido establecerse de manera total, por su condición cambiante, inherente al momento histórico que vive. Una definición de la posmodernidad debería llevar implícitos, entre otros elementos, aquellos que le proporcionan la filosofía, la antropología filosófica y la filosofía del lenguaje. Sin embargo, 
se intentará bordear algunos conceptos que permitan entender esta doctrina filosófica. ${ }^{1}$

Para explicar lo posmoderno, conviene retroceder y analizar a aquellos pensadores que cuestionaron la racionalidad de la modernidad. Sin duda la figura más significativa es Friedrich Nietzsche y su teoría del nihilismo.2 Para Nietzsche, el nihilismo ocurre en la medida en que el hombre abandona el centro y se coloca en un punto cualquiera; cuando tiene lugar la desvalorización de los valores supremos: cuando se proclama la muerte de Dios; cuando el mundo es convertido en fábula y se atribuye a esta la antigua dignidad metafísica del mundo verdadero, o cuando la experiencia pierde la autenticidad y se emancipa de cualquier valor último (De Carvalho, 1994:14). En síntesis, de acuerdo con Nietzsche, ya no se puede tener seguridad de

1. Para facilitar el análisis conviene distinguir entre posmodernismo, que acentúa el aspecto cultural, y posmodernidad, dónde el énfasis se pone en lo social. Posmodernidad como una socio-histórica época, posmodernismo como una configuración de arte, contra la modernidad y posmoderno: el conocimiento como una crítica a la epistemología moderna.

2. El nihilismo es el proceso final del racionalismo. Es la voluntad consciente del hombre de destruir su pasado y controlar su futuro. Es la modernidad en su forma extrema. (Bell, 1994:18). nada: la verdad es una ficción, la moralidad una mentira, Dios no existe, todo lo que queda es aceptar el nihilismo, vivir sin engaños, ni fingimientos. Se eliminan los valores fundamentales en los que está cimentado el mundo moderno.

Martin Heidegger es otro filósofo de lo que podríamos llamar "prehistoria" de la posmodernidad. A él le interesa sobre todo la naturaleza del pensamiento en los seres humanos. Comparte el interés de Nietzsche por la filosofía de la diferencia, pero va más allá y declara que el Ser no es la verdad, sino el verdadero objeto de la filosofía. "En la actualidad el humanismo se halla en crisis precisamente porque ha sustituido a Dios por la humanidad en el centro del universo, afirmaba Heidegger". Para él, la forma de avanzar requiere reconciliarse con nuestra condición: ni la metafísica, ni el humanismo ni la tecnología pueden constituir bases sólidas para la vida (Lyon, 1996:26).

Este aporte conduce a pensar que el fin de la modernidad no significa un declive decadente y un colapso cultural, por el contrario, Heidegger considera que más que un final es una oportunidad para iniciar la reconstrucción. 


\section{Surgimiento de la posmodernidad}

Para los posmodernos3 la teoría moderna abarca desde Descartes y las teorías de la Ilustración, hasta las teorías sociales de Comte, Marx, Weber y otros.

La modernidad se propuso conquistar el mundo en nombre de la razón, la certeza y el orden social, los cuales se asentarían sobre una nueva base económica: el capitalismo.

Antes de la Ilustración, el mundo premoderno se regía por la providencia,4 según lo cual se niega el movimiento cíclico en la historia y se despierta la esperanza en el futuro, más que resignación o pesimismo. "La modernidad es ante todo un proceso de secularización: el lento paso de un orden recibido a un orden producido". (Lechner, 1988:5). El mundo moderno trastoca esta providencia por la fe en la

3. Para Lyotard hay 3 condiciones del conocimiento moderno: el invocar a metanarraciones para legitimar el reclamo fundamentalista, el inevitable resultado de legitimación, deslegitimación y exclusión y un deseo por homogéneas y morales prescripciones. (Traducción libre, tomado de Best S. y Kellner D.1991. "Posmodern Theory".)

4. Entendemos por providencia: el cuidado que Dios dispensa su creación, vigilando el progreso de la historia, de forma que esta siempre avance hacia un objetivo concreto. (Lyon, 1996:18). razón y el progreso, y más tarde en el nihilismo. "Al acentuar la razón y restar importancia a la intervención divina se estaban poniendo las semillas de una variante secular de la providencia, la idea del progreso. La certeza de la evidencia que nos proporcionaban los sentidos sustituyó a la certeza de las leyes divinas y preparó el camino a concepciones modernas del mundo científico" (Lyon, 1996:19).

El proyecto moderno elimina así la incertidumbre y la ambivalencia; sin embargo, la razón autónoma siempre tendría dudas, estaba obligada si quería evitar caer en el "dogma". Es por ello, que la relatividad del pensamiento quedó incorporada en el pensamiento moderno.

La idea de la razón objetiva seculariza la vida: la razón sobre la fe, esto permite las conquistas del espíritu científico, la sociedad se reconstruye a partir de decisiones racionales y libres.

Sin embargo, a partir de los años sesentas, la fe en el progreso se derrumba; la otra cara del industrialismo se reveló amenazadoramente, como por ejemplo: la degradación del medio ambiente, el agotamiento de recursos irremplazables y el deterioro de la capa de ozono, el derrumbe del sistema colonial. Se comienza a cuestio- 
nar todas las doctrinas heredadas: Surgen nuevas voces, y nuevos movimientos sociales, comienza poco a poco a desintegrarse el "mundo racionalizado" que pregonaba la modernidad.

Para Agnes Heller, como teoría social, el posmodernismo nació en 1968: "Para decirlo de alguna manera, el posmodernismo fue la creación de la generación de la alienación desilusionada con su propia percepción del mundo" (Heller, 1996:239).

El 68 fue la época de los movimientos de la juventud en Francia, donde surgen las protestas por el antiguo régimen, los hijos e hijas se revelan ante la autoridad patriarcal, se da la guerra de Vietnan, el movimiento hippie y los Beatles, la Primavera de Praga, la invasión a Hungría; se está gestando una nueva era. Pero, como lo apunta Heller, esta fue una generación desilusionada, porque las metanarraciones o metadiscursos5 que pregonaban la utopía de un mundo distinto fracasaron.

El posmodernismo significa, por tanto, un desencantamiento con la modernidad y su concepción de mundo.

5. Son metarraciones o metadiscursos: los discursos que, partiendo por lo general de una sola disciplina, sin diálogo serio con los aportes de las demás, pretenden encerrar en sí y dar conocimiento de la realidad (Robles, 1995: 49).

\section{¿Qué se entiende por posmodernidad?}

El pos- de posmodernidad no significa un proceso de retroceso o salto hacia atrás, ni retroalimentación, sino que se refiere a vivir después. "Esta descripción temporal-espacial deliberadamente vaga (es especial porque "después" significa también que ya no hay normas válidas, que las virtudes han desaparecido y que, por un lado, las personas actúan de modo instrumental mientras que por otro encajan en roles y requisitos externos e institucionales sin tener en absoluto ninguna motivación moral intrínseca" (Féher, 1994:24).

Hay una pérdida de confianza en la idea del progreso y en el futuro que depara tiempos mejores. El desarrollo de las tecnologías se vuelve un medio para incrementar la enfermedad, no para acabar con ella. No existe ya un horizonte de universalización, de emancipación. La modernidad entra en crisis porque su principal fuerza legitimadora, el historicismo, se rompe: ya no hay significado ni significantes mediante los que la modernidad pudiera obtener su legitimación, no hay horizontes prometedores. Como se ha dicho, la posmodernidad y el posmodernismo surgen después de los años sesenta, cuando las grandes uto- 
pías no se concretaron. El presente es el único tiempo, no hay oportunidades de soñar con tiempos mejores; la modernidad estalla.

Alain Touraine identifica cuatro corrientes de pensamiento dentro de la posmodernista, cada una de las cuales representa una forma de ruptura con la ideología modernista:

\section{La primera define la posmodernidad como hipermodernidad}

Considera la modernidad como un movimiento que no cesa de acelerarse, las vanguardias son cada vez más efímeras. La producción cultural se vuelve vanguardista gracias a un consumo cada vez más rápido de lenguajes y signos. Es una cultura caleidoscópica que no renuncia a la modernidad, pero que la reduce a la construcción de disposiciones técnicas que solo llaman la atención por su novedad y sus proezas técnicas, superadas con rapidez.

\section{Crítica al modernismo social y político de la modernidad}

Se critican las ideas revolucionarias y los contramodelos de sociedades cuya realización exigía la interven-

ción de un poder absoluto, cuando más completa era la ruptura que debía efectuarse. El concepto de revolución se asocia a la moderni- dad. El neoliberalismo que triunfa en la vida económica y política en los ochentas y el posmodernismo cultural son productos paralelos de la descomposición del izquierdismo.

Esta corriente de pensamiento posmoderno niega lo social (disolución de lo social). La situación pos social es el producto de una completa separación entre la instrumentalidad y el sentido: la primera es gestionada por las empresas económicas o políticas que concurren en los mercados; el segundo se ha vuelto puramente privado (Touraine, 1994:242). El principio de regulación de la vida social es la tolerancia, pues se produce una disociación entre lo privado y público.

Dentro de esta corriente, la política ya no pretende cambiar la vida, ejemplo de ello es que los parlamentos dejan de ser los representantes de las demandas sociales y se convierten en los lugares donde se define, de forma cada vez más pragmática, la base de apoyo del poder ejecutivo, que, por lo que él refiere, es un gestor. Esta visión de política explica en parte lo que pasa en la Asamblea Legislativa costarricense, donde el Poder Legislativo se convierte en un órgano de la Casa Presidencial y resulta entonces totalmente válido preguntarse por lo que sucede en realidad con las demandas de las mayorías. 
Los actores cesan de ser sociales, se vuelven hacia ellos mismos, hacia la búsqueda narcisista de su identidad, sobre todo cuando no están integrados en la clase media, que se define antes por la profesión y el consumo, que por normas de conducta social (Touraine, 1994:243).

El campo pos social está conformado por las tres grandes tendencias de nuestro tiempo:

- el triunfo de una intrumentalidad convertida en acción estratégica

- $\quad$ el repliegue a la vida privada

- la globalización ecologista de los problemas planteados por la tecnología.

\section{Ruptura con el historicismo:}

Romper con el historicismo modernista significa:

- la sustitución de la sucesión de las formas culturales por su simultaneidad

- el rechazo a toda idea de totalidad

- $\quad$ la referencia a un pluralismo cultural, que se quiebra con la concepción moderna de la unidad de una cultura. Este es precisamente el propósito de la televisión, que tiene la capacidad de volver próximo y simultáneo lo que está lejos en el tiempo o en el espacio.

- Este "ecologismo cultural" se opone al universalismo de la ideología modernista.

\section{Destrucción de la}

\section{representación}

\section{modernista del mundo}

Se rechaza la separación entre la alta cultura social, política y estética. Hay una consigna antiestética. Se rechaza también la construcción de imágenes del mundo.

"El pensamiento posmoderno ya no acepta situar al ser humano ante el mundo, mirándolo, reproduciéndolo en imágenes, porque lo sitúa en el mundo, sin distancia, o más bien volviéndolo a poner esa distancia que supone la existencia previa del objeto por la construcción de una red de comunicaciones, de un lenguaje entre el pintor, el arquitecto o el escritor y los objetos" (Touraine, 1994:246).

El posmodernismo señala la destrucción del reinado de la técnica y la racionalidad instrumental. La experiencia y el lenguaje reemplazan los proyectos y los valores, la acción colectiva pierde toda existencia, lo mismo que el sentido de la historia. "El posmo- 
dernismo ilumina un hecho: que la hiperindustrialización actual no entraña la formación de una sociedad hiperindustrial: al contrario, entraña la disociación del universo cultural y del universo técnico. Lo cual destruye la idea de la interdependencia de la economía, de la política y de la cultura "moderna" (Touraine, 1994:247).

\section{La política desde la posmodernidad}

Para efectos de este trabajo deberá caracterizarse la política desde la posmodernidad, con base en lo expuesto por Heller y Feher.

La posmodernidad no es un período histórico, ni se trata de una tendencia con características bien definidas. Post significa el tiempo y el espacio privado-colectivo más amplio de la modernidad. De acuerdo con estos autores, los posmodernistas viven entre modernos y premodernos.

El fundamento de la posmodernidad consiste en contemplar el mundo como una pluralidad de espacios y temporalidades.

La política posmoderna predomina en lo social y político de lo funcional sobre lo estructural; se trata de la total desaparición de una política basada únicamente en intereses y percepciones de clase.
El Estado moderno se caracteriza por el choque suscitado por cuestiones económicas, entre organizaciones de clase y el Estado.

Política posmoderna debe entenderse como lo que está después de los argumentos de clase. Genera un especial énfasis político sobre el presente. Esta dominante temporalidad de la política posmoderna tiene ciertas implicaciones: cualquier tipo de política redentora es incompatible con la condición política de la posmodernidad. "La limitación posmoderna hacia el presente como nuestra única eternidad también excluye los experimentos con "saltos de la nada", es decir, los intentos de la trascendencia absoluta de la modernidad" (Heller y Fehér, 1994:152). Como se dijo, la posmodernidad nace precisamente de su desencantamiento con el socialismo y su concepción de una mejor vida.

Otra característica de la condición posmoderna de la política es que se lleva a cabo un reciclaje de nuevas teorías (o soluciones políticas), se recuperan todas las historias, las sabidurías pasadas y en apariencia extintas y todos los esfuerzos colectivos que Europa ha tratado de ocultar. Los posmodernistas relativizan el pensamiento. Hay una búsqueda constante de raíces en la condición posmoderna, una búsqueda no holística, un rechazo a las grandes narrativas. 
La política posmoderna tiene por premisa la aceptación de la pluralidad de culturas y discursos. "La caída de la gran narrativa es una invitación directa a la cohabitación entre varias narrativas pequeñas (locales, culturales, étnicas, religiosas, ideológicas)" (Heller y Fehér, 1994:153-154).

Se rechaza entonces el universalismo político, lo que favorece que ya no exista una tierra incógnita en la geografía y el fin de un período de desvergonzada supremacía blanca.

La desintegración de la gran narrativa de secularización es un hecho de la condición política posmoderna; ejemplo de ello es el renacimiento religioso que hace campaña por la vida -los teólogos de la liberación-. La secularización que pregona el mundo moderno fue la gran "religión del ateo" $\mathrm{y}$, sin duda, una de las mayores narrativas representativas de la escena política después de la Revolución Francesa, cuando se hacían promesas redentoras, tales como crear una sociedad transparente y hacer el paraíso en la tierra.

El rasgo posmoderno es el renacimiento religioso, el cual es profundamente pluralista y a menudo también ecuménico.

\section{¿Política Posmoderna en América Latina?}

¿Es la posmodernidad una moda intelectual de Europa y Estados Unidos? ¿Es válida solo para tales zonas geográficas? No cabe duda de que esta forma de pensamiento social es una noción controvertida y demasiado temprana para evaluar el alcance de su discusión, pero sí se debe reconocer que la posmodernidad, como se vio anteriormente, aporta elementos para entender las realidades latinoamericanas. Por ejemplo, existe un estado de ánimo diferente a las décadas pasadas, una nueva sensibilidad que permite reconocer las particularidades de los pueblos.

Uno de los principales conceptos que aporta la posmodernidad es el desencanto con la modernidad, el rechazo a nociones de totalidad y una vanguardia que desplaza la tradición. Denuncia al progreso como una ilusión, lo relativiza y lo vacía de contenido. El futuro termina diluyéndose en el presente y deja de tener valor; las metanarraciones de los contramodelos modernistas como el socialismo crearon expectativas por las que muchos hombres y mujeres murieron, sin embargo, se diluyeron y se convirtieron, como apunta Lyotard, en narrativas históricas. 
La política posmoderna elogia la heterogeneidad como un rechazo a toda idea de colectividad, un ataque a la falsa homogenización que impone la racionalidad.

Sin embargo, en América Latina, el proyecto político modernista es el imperante: se silencian las voces, la homogenización es la regla; se impone un tipo de cultura, de religión, los indígenas son marginados y vistos como minorías; se impone una lengua, un tipo de orden y una institucionalidad que no corresponde a las necesidades de las mayorías. Se reduce la política a una racionalidad valorativa neutral.

No obstante, a pesar del modelo homogenizador, van surgiendo demandas por una pluralidad radical y se rechaza una lógica política única. Ello se expresa en la política informal que introducen los nuevos movimientos sociales, con su renuncia a la institucionalización y formalización. Ejemplo de esto son los grupos ecologistas, los indigenistas, las feministas. Hoy ha desaparecido el optimismo iluminista acerca de la convergencia de la ciencia, moral, y arte, para lograr el control de las fuerzas naturales, el progreso social y la felicidad del ser humano.

La democracia en nuestros países ha estado atravesada por una desconfianza de la pluralidad. En tanto cuestionamiento indebido de la "unidad nacional", el posmodernismo lleva a revalorar positivamente esta diferencia social.

\section{CONCLUSIONES}

La teoría posmoderna problematiza sobre las cuestiones claves relativas a los cambios sociales contemporáneos. Invita a participar en un debate sobre la naturaleza y la dirección de las sociedades actuales en un contexto globalizado.

Con el debate de la posmodernidad se estimula una revaloración de la modernidad, que obliga a tomar juicios sobre esta. Se rechazan las nociones de totalidad y se produce una ruptura con el racionalismo instrumental que la caracteriza.

El desencanto posmoderno sugiere meditar sobre la importancia del multiculturalismo, lo que significa la existencia de muchas opiniones, la pluralidad y heterogeneidad que por tantos años estuvo oculta por la homogeneidad pregonada por la modernidad.

¿Se puede hablar del ocaso de la modernidad en América Latina? No todavía, pues las fracturas son pequeñas; sin embargo, los órganos represivos son más fuertes e impiden que las voces se levanten. 
Hay un desencanto con una manera de hacer política, pues ya que esta ha sido incapaz de generar ciudadanía económica, los pueblos latinoamericanos comparten pobreza y exclusión social. Hay un desencanto con el tipo de democracia instaurado en nuestros países, un desencanto con el estilo gerencial-tecnocrático del Estado. Surge la apatía y la desilusión ante la imposibilidad de un futuro mejor. Resulta oportuno preguntarse ¿es posible pensar en un futuro mejor, sin caer en las grandes utopías socialistas que tanta sangre y muerte produjeron?

No se puede dar cabida a las ideas apocalípticas, por el contrario, en la medida en que haya esperanza, hay vida.

Los diferentes grupos sociales como los ecologistas, feministas y comités de derechos humanos demandan una pluralidad racional; es hora ya de que los Estados latinoamericanos los oigan y rompan de una vez por todas con la concepción moderna de exclusión de las mayorías.

\section{BIBLIOGRAFÍA}

Barberousse, Paulette. (2002).Globalización y Posmodernidad: Desafíos al aprendizaje humano. En: Revista Educación.Vol. $26(2)$.
Bell Daniel.(1994). Las contradicciones culturales del capitalismo. España: Alianza Editorial. (Quinta impresión).

Best Steven y Douglas Kellner. (1991). Postmodern Theory.Critical Interrogations. Estados Unidos: Guilford Press.

Carvajal, Guillermo. et al. (2003). Globalización y Cultura: Una aproximación a los problemas del mundo en la posmodernidad. Costa Rica: Editorial Guayacán.

De Carvalho, José. “La antropología y el nihilismo filosófico posmoderno". En: Revista Alteriades 4(8): pp. 13-29.

Díaz, Esther. Postmodernismo. (2000). Argentina: Editorial Biblos.

Heller, Agnes y Ferenc Fehér. (1992). El péndulo de la modernidad. Una lectura de la era moderna después de la caída del comunismo. España: Ediciones Península.

Heller, Agnes y Ferenc Fehér.(1994). Políticas de la posmodernidad. Ensayos de crítica cultural. España : Ediciones Península. (Segunda Edición).

Lechner, Norbert.(1989). “Un desencanto llamado posmoderno". Documento de trabajo, Número 369. FLACSO, Chile.

Lyon, David. (1996). Posmodernidad. España: Alianza Editorial.

Lyotard, Jean F. (2000). La Condición Posmoderna. Informe sobre el saber. España: Ediciones Cátedra. (Tercera Edición).

Jameson, Frederic. Posmodernidad y globalización. En: http://biblioweb.sindominio.net/pensamiento/jameson.html.

Jiménez, Alexander (compilador).(1995). "Del buiho a los gorriones. Ensayos sobre la posmodernidad. Costa Rica: Ediciones Guayacán.

Touraine, Alain. (1993).Crítica de la modernidad. España: Ediciones Temas de Hoy. 